\title{
ESBL carriage in pig slaughterhouse workers is associated with occupational exposure
}

\author{
W. DOHMEN ${ }^{1}$, L. VAN GOMPEL ${ }^{1}$, H. SCHMITT ${ }^{1}$, A. LIAKOPOULOS ${ }^{2,3}$, \\ L. HERES ${ }^{4}$, B. A. URLINGS ${ }^{4}$, D. MEVIUS ${ }^{2,3}$, M. J. M. BONTEN ${ }^{5}$ AND \\ D. J. J. HEEDERIK ${ }^{1}$ \\ ${ }^{1}$ Division of Environmental Epidemiology, Institute for Risk Assessment Sciences, Utrecht University, Utrecht, \\ the Netherlands \\ ${ }^{2}$ Department of Bacteriology and Epidemiology, Central Veterinary Institute of Wageningen UR, Lelystad, \\ the Netherlands \\ ${ }^{3}$ Department of Infectious Diseases and Immunology, Faculty of Veterinary Medicine, Utrecht University, \\ Utrecht, the Netherlands \\ ${ }^{4}$ Vion Food, Boxtel, the Netherlands \\ ${ }^{5}$ Department of Medical Microbiology, University Medical Center Utrecht, Utrecht, the Netherlands
}

Received 18 October 2016; Final revision 27 February 2017; Accepted 23 March 2017;

first published online 2 May 2017

\section{SUMMARY}

We investigated the prevalence of extended-spectrum $\beta$-lactamase (ESBL) carriage in slaughterhouse workers and the association with occupational exposure to slaughter animals and products. Stool samples from 334 employees in a Dutch pig slaughterhouse were obtained.

Presence of ESBL was determined by selective plating, microarray analysis, and gene sequencing. Questionnaires were used to collect personal and occupational information. The overall prevalence of ESBL carriage was $4 \cdot 8 \%$ (16/334). All ESBL-producing isolates were Escherichia coli. The ESBL genes detected were $b l a_{\mathrm{CTX}-\mathrm{M}-1}(n=8), b_{\mathrm{CTX}-\mathrm{M}-15}(n=3), b l a_{\mathrm{CTX}-\mathrm{M}-27}(n=2)$, $\operatorname{bla}_{\mathrm{CTX}-\mathrm{M}-24}(n=1), \operatorname{bla}_{\mathrm{CTX}-\mathrm{M}-55}(n=1)$, and $\operatorname{bla}_{\mathrm{SHV}-12}(n=1)$. A higher prevalence of ESBL was seen in workers in jobs with as tasks 'removal of lungs, heart, liver, tongue' (33\%), and 'removal of head and spinal cord' (25\%). For further analysis, participants were divided in two groups based on potential exposure to ESBL as related to their job title. One group with an assumed higher exposure to ESBL (e.g. stable work, stabbing, dehairing, removal of organs) and another group with an assumed lower exposure to ESBL (e.g. refrigeration, packaging and expedition). In the 'higher exposure' group, ten out of $95(10 \cdot 5 \%)$ were carrying ESBL vs. six out of $233(2 \cdot 6 \%)$ in the 'lower exposure' group. Human ESBL carriage was significantly associated with job exposure in the slaughterhouse (OR 4·5, CI 1·6-12.6). Results suggest that ESBL carriage in slaughterhouse workers overall is comparable with the Dutch population. Within the slaughterhouse population a difference in carriage exists depending on their position along the slaughter line and tasks involved.

Key words: Antimicrobial resistance, bla $_{\mathrm{CTX}-\mathrm{M}-1}$, occupational epidemiology, pig abattoir workers, zoonosis.

\footnotetext{
* Author for correspondence: W. Dohmen, Institute for Risk Assessment Sciences, Yalelaan 1, 3584 CM Utrecht, The Netherlands. (Email: w.dohmen@uu.nl)
} 


\section{INTRODUCTION}

In humans, infections with extended-spectrum $\beta$-lactamase (ESBL)-producing Enterobacteriaceae are associated with increased burden of disease and costs [1]. Livestock can carry ESBL-producing Enterobacteriaceae with $b l a_{\mathrm{CTX}-\mathrm{M}-1}$ as the most prevalent ESBL gene found in Europe [2]. ESBL-producing Enterobacteriaceae can be transferred from animals to humans through food or direct contact [3, 4]. Direct contact with livestock mainly occurs in an occupational setting. In farmers, carriage of ESBL-producing Enterobacteriaceae is associated with the presence of ESBL-producing Enterobacteriaceae in animals $[3,5,6]$. Slaughterhouse workers might also be occupationally exposed to ESBL-producing Enterobacteriaceae. Depending on the job task, slaughterhouse workers have frequent contact with live animals, animal carcasses or animal products. ESBL-producing Enterobacteriaceae have frequently been found in intestinal content of pigs at the slaughter level [7-9]. Besides that, ESBL-producing Enterobacteriaceae can also be detected on pig carcasses at the slaughterhouse [10]. A higher prevalence of antimicrobial resistant Escherichia coli in pig slaughterhouse workers has been reported [11-13]. However, carriage of ESBL-producing Enterobacteriaceae in slaughterhouse workers has not been established yet. In addition, E. coli contamination on carcasses seems to be reduced during the slaughter process $[14,15]$. Therefore exposure, and as a consequence prevalence of carriage, of ESBL-producing Enterobacteriaceae might be dependent on the working area and job task within a slaughterhouse.

We investigated the prevalence of ESBL carriage in pig slaughterhouse workers and the association with occupational exposure.

\section{MATERIALS AND METHODS}

\section{Study design}

A large pig slaughterhouse in the southern part of the Netherlands (Vion, Boxtel) was visited by the researchers during 1 week in June 2015. All slaughterhouse workers with a slaughter process related job were asked to participate in the study by the use of flyers and information on screens. In total, 1781 eligible slaughterhouse workers were employed by the slaughterhouse at the time of the study. Participants were asked to provide a faecal specimen and to fill out a consent form and a questionnaire containing items on personal and occupational information, including job function in the slaughterhouse. Due to the heterogeneity in nationality of the slaughterhouse workers (14 different nationalities), the flyer, questionnaire and consent form were provided in 11 different languages. Participants were motivated for participation with a voucher worth of 25 euro. Faeces samples and documents were handed in to the researchers at the slaughterhouse within the same week. At the same day, for the purpose of detecting ESBL-producing Enterobacteriaceae, $<1 \mathrm{~g}$ faeces was collected from the tube by the use of a swab and stored in the refrigerator immediately. All swabs were sent refrigerated in one batch to the laboratory. The authors assert that all procedures contributing to this work comply with the ethical standards of the relevant national and institutional committees on human experimentation and with the Helsinki Declaration of 1975, as revised in 2008. The Medical Ethical Committee of the University Medical Centre Utrecht confirmed that the Medical Research Involving Human Subjects Act did not apply for this study and that therefore an official approval by the Medical Ethical Committee was not required (Protocol no. 14-346/C). All participants gave written informed consent.

\section{Laboratory analysis}

At the day of arrival in the laboratory, all faecal specimens were analysed for the presence of ESBLproducing Enterobacteriaceae by selective plating. Samples were suspended in $10 \mathrm{ml}$ LB-medium with cefotaxime $(1 \mu \mathrm{g} / \mathrm{ml})$ and incubated overnight at $37^{\circ} \mathrm{C}$. Approximately $10 \mu \mathrm{l}$ of each suspension was streaked on MacConkey agar plates with cefotaxime $(1 \mu \mathrm{g} / \mathrm{ml})$ and incubated overnight at $37^{\circ} \mathrm{C}$. Individual colonies with different morphology were selected for bacterial species identification performed by MALDI-TOF MS. All isolates suspected of producing ESBLs were selected for further molecular analysis to confirm the presence of ESBL genes. DNA was isolated using DNeasy 96 Blood \& Tissue Kit (Qiagen, Hilden, Germany). A $\beta$-lactamase microarray assay (Check-MDR CT101, Checkpoints, Wageningen, the Netherlands) was used to detect genes encoding carbapenemases (KPC and NDM), ESBLs (CTX-M groups 1, 2, 8/25 and 9, TEM, SHV) and AmpCs (CMY-1 /MOX, ACC, DHA, ACT/MIR, CMY-2, FOX). DNA from ESBL/AmpC microarray positive isolates was amplified and sequenced with group-specific primers to determine 
Table 1. Distribution of slaughterhouse workers and ESBL carriage over different job tasks

\begin{tabular}{|c|c|c|c|c|}
\hline & \multirow{2}{*}{ Job task } & \multicolumn{3}{|c|}{ Frequency } \\
\hline & & Total & $\begin{array}{l}\text { ESBL } \\
\text { carriers }\end{array}$ & $\begin{array}{l}\text { Non-ESBL } \\
\text { carriers }\end{array}$ \\
\hline \multirow[t]{10}{*}{ 'Higher exposure' group } & Stable/lairage part, stunning part & 12 & 0 & 12 \\
\hline & Stabbing and bleeding part & 5 & 0 & 5 \\
\hline & Dehairing and hanging part & 6 & 1 & 5 \\
\hline & Removal of penis, stab wound and loosing/ligation anus (anal duct) & 6 & 0 & 6 \\
\hline & Evisceration & 10 & 1 & 9 \\
\hline & Removal of lungs, hart, liver, tongue & 12 & 4 & 8 \\
\hline & Inspection platform & 8 & 0 & 8 \\
\hline & Dressing (first, second), removal abdominal fat, diaphragm & 17 & 1 & 16 \\
\hline & Removal of head, spinal cord & 8 & 2 & 6 \\
\hline & Organs (tongues, hearts, livers, kidneys) & 11 & 1 & 10 \\
\hline \multirow[t]{6}{*}{ 'Lower exposure' group } & Refrigeration and cooling area & 26 & 0 & 26 \\
\hline & Cutting room & 75 & 2 & 73 \\
\hline & Deboning area & 63 & 1 & 62 \\
\hline & Packaging & 30 & 2 & 28 \\
\hline & Expedition (moving and shipment) & 8 & 0 & 8 \\
\hline & Other (e.g. technical services) & 31 & 1 & 30 \\
\hline
\end{tabular}

the exact gene type [16]. DNA sequences were interpreted with Basic Local Alignment Search Tool (National Center for Biotechnology Information). Plasmids encoding the ESBL (or AmpC) genes were determined using a transformation-based approach. Purified plasmid DNA was electro-transformed into E. coli DH10B cells (Invitrogen, Van Allen Way, CA, USA) under the following conditions: $1.25 \mathrm{kV} /$ $\mathrm{cm}, 200 \Omega, 25 \mu$ Far [17]. When strains recovered from workers were not giving transformants (workers 12 and 15), conjugation was performed using the plasmid-free rifampin-resistant E. coli E3110 as a recipient strain for liquid-mating assays in 1:1 ratio as previously described [17]. Transformants were selected on lysogeny broth (LB) agar supplemented with cefotaxime $(1 \mu \mathrm{g} / \mathrm{ml})$, whereas transconjugants on LB agar with rifampin $(100 \mu \mathrm{g} / \mathrm{ml})$ and cefotaxime $(1 \mu \mathrm{g} / \mathrm{ml})$. PBRT (PCR-based replicon typing) on the transformants and multilocus sequence typing (MLST) on the parental strains were performed to analyse genetic similarities of isolates and plasmid content [17].

\section{Statistical analysis}

Slaughterhouse workers were classified as ESBL positive, if any ESBL gene was detected in their faeces sample. Statistical analyses were performed using SAS version 9.4 (SAS Institute Inc., Cary, NC, USA). The association between carriage of ESBL-producing Enterobacteriaceae in humans and job function was calculated with logistic regression analysis (proc GENMOD). For this analysis, participants were divided in two groups based on potential exposure within their specific job task. One group with an assumed higher exposure to ESBL-producing Enterobacteriaceae consisted of job tasks in the early stages of the slaughter process (e.g. stable work, stabbing, dehairing, removal of organs, i.e. direct contact with pigs and pig carcasses). The other group, assumed to have lower exposure to ESBL-producing Enterobacteriaceae, consisted of job tasks in the latter stages of the slaughter process (e.g. refrigeration, packaging, expedition, i.e. contact with meat or meat products) (see Table 1). When participants reported to have more than one job function, they were assigned to the first job function at the slaughter line. Other potential risk factors such as nationality, consumption of raw meat, hospitalization, use of antimicrobials, living on a farm, travelling, and potential confounder's age, gender and smoking were analysed univariately as well and selected for multivariate analysis when $P$-value was below $0 \cdot 2$. Model selection was performed by a backward procedure. Model fit was checked with the QIC-statistic (Quasi-likelihood under the Independence model Criterion). The final model retained variables significant at $P \leqslant 0 \cdot 05$.

\section{RESULTS}

Human stool samples from 334 employees were obtained. Most of the participants were male and did 
Table 2. Overview of participant characteristics and Odds Ratios from the univariate analysis for the probability of ESBL carriage

\begin{tabular}{|c|c|c|c|c|}
\hline \multirow[b]{2}{*}{ Characteristics of participants } & \multicolumn{3}{|c|}{ Frequency } & \multirow[b]{2}{*}{ OR $(95 \% \mathrm{CI})$} \\
\hline & Total & ESBL carriers & Non-ESBL carriers & \\
\hline \multicolumn{5}{|c|}{ Exposure group in slaughter process $(n=328)$} \\
\hline 'Higher exposure' group & 95 & 10 & 85 & $4.45(1.57-12 \cdot 62)$ \\
\hline 'Lower exposure' group & 233 & 6 & 227 & Ref. \\
\hline Age (mean) $(n=328)$ & $39 \cdot 8$ & $38 \cdot 1(n=16)$ & $39 \cdot 9(n=312)$ & $0.99(0.94-1.03)^{*}$ \\
\hline \multicolumn{5}{|l|}{ Gender $(n=324)$} \\
\hline Male & 276 & 14 & 262 & $2 \cdot 51(0 \cdot 32-19 \cdot 54)$ \\
\hline Female & 48 & 1 & 47 & Ref. \\
\hline \multicolumn{5}{|l|}{ Nationality $(n=305)$} \\
\hline Non-Dutch ${ }^{\dagger}$ & 245 & 12 & 233 & $0.98(0 \cdot 27-3 \cdot 58)$ \\
\hline Dutch & 60 & 3 & 57 & Ref. \\
\hline \multicolumn{5}{|c|}{ Consumption of raw meat $(n=294)$} \\
\hline Yes & 106 & 4 & 102 & $0 \cdot 70(0 \cdot 21-2 \cdot 28)$ \\
\hline No & 188 & 10 & 178 & Ref. \\
\hline \multicolumn{5}{|c|}{ Hospitalization in the past 12 months $(n=295)$} \\
\hline Yes & 32 & 2 & 30 & $1 \cdot 28(0 \cdot 28-5 \cdot 96)$ \\
\hline No & 263 & 13 & 250 & Ref. \\
\hline \multicolumn{5}{|c|}{ Use of antimicrobials in the past 12 months $(n=323)$} \\
\hline Yes & 48 & 3 & 45 & $1.34(0.37-4.90)$ \\
\hline No & 275 & 13 & 262 & Ref. \\
\hline \multicolumn{5}{|l|}{ Living on a farm $(n=297)$} \\
\hline Yes & 17 & 0 & 17 & NE \\
\hline No & 280 & 13 & 267 & \\
\hline \multicolumn{5}{|c|}{ Travelling in the past 12 months $(n=311)$} \\
\hline Yes & 216 & 7 & 209 & $0 \cdot 36(0 \cdot 13-1 \cdot 04)$ \\
\hline No & 95 & 8 & 87 & Ref. \\
\hline \multicolumn{5}{|l|}{ Smoking $(n=321)$} \\
\hline Yes & 140 & 3 & 137 & $0 \cdot 31(0 \cdot 09-1 \cdot 12)$ \\
\hline No & 181 & 12 & 169 & Ref. \\
\hline
\end{tabular}

Ref., Reference category; NE, Not estimated due to empty cells.

* Per 1 year increase.

$\dagger$ Not from the Netherlands: Cape Verdean $(n=1)$, Ghanese $(n=1)$, Hungarian $(n=46)$, Latvian $(n=3)$, Polish $(n=119)$, Portugese $(n=12)$, Romanian $(n=41)$, Slovakian $(n=20)$, Turkish $(n=2)$.

not originate from the Netherlands (Table 2). The overall prevalence of ESBL carriage was $4.9 \%$ (16/334), and all ESBL-producing isolates were $E$. coli. The ESBL genes detected were bla $_{\mathrm{CTX}-\mathrm{M}-1}(n=8)$, bla $_{\mathrm{CTX-M-15}}(n=3), b l a_{\mathrm{CTX}-\mathrm{M}-27}(n=2)$, bla $_{\mathrm{CTX}-\mathrm{M}-24}$ $(n=1)$, bla $_{\mathrm{CTX}-\mathrm{M}-55}(n=1)$ and bla $_{\mathrm{SHV}-12}(n=1)$. In addition, three other slaughterhouse workers carried an AmpC gene $\left[\operatorname{bla}_{\mathrm{CMY}-2}(n=2)\right.$ and $\left.b l a_{\mathrm{DHA}-1}(n=1)\right]$. Plasmids encoding ESBL genes were assigned to multi-F $(n=6), \mathrm{I} 1 \alpha(n=4), \mathrm{N}(n=3)$ and $\mathrm{K}(n=1)$ replicon types. For two isolates, transformation and conjugation experiments failed to give transformants and transconjugants suggesting the chromosomal location of these genes. MLST revealed that ESBLproducing $E$. coli belonged to 11 different sequence types (STs), with ST131 $(n=4)$, ST88 $(n=3)$ and ST93 $(n=3)$ as the most frequent ones. All molecular aspects are listed in Table 3.

ESBL carriage was not equally distributed across different jobs in the slaughterhouse. A higher prevalence of ESBL seemed to appear in workers involved in 'removal of lungs, heart, liver, tongue' (33\%) and 'removal of head and spinal cord' (25\%) (see Table 1). In the 'higher exposure' group, ten out of $95(10 \cdot 5 \%)$ were carrying ESBL vs. six out of 233 $(2 \cdot 6 \%)$ in the 'lower exposure' group. Human ESBL carriage was significantly associated with job exposure in the slaughterhouse (odds ratio (OR) 4.45, CI 1.5712.62). Smoking was univariately and negatively borderline significantly associated with ESBL carriage 
Table 3. Molecular aspects of ESBL/AmpC positive E. coli isolates from slaughterhouse workers

\begin{tabular}{|c|c|c|c|c|}
\hline $\begin{array}{l}\text { Slaughterhouse } \\
\text { worker }\end{array}$ & $\begin{array}{l}\text { ESBL/AmpC } \\
\text { gene }\end{array}$ & $\begin{array}{l}\text { Plasmid rep/ } \\
\text { inc-type }\end{array}$ & $\begin{array}{l}\text { Sequence types } \\
\text { (ST) }\end{array}$ & Job task \\
\hline 1 & bla $_{\mathrm{CTX}-\mathrm{M}-1}$ & $\operatorname{IncI} 1 \alpha$ & 88 & Evisceration \\
\hline 2 & bla $a_{\mathrm{CTX}-\mathrm{M}-1}$ & $\operatorname{IncI} 1 \alpha$ & 88 & Removal of lungs, hart, liver, tongue \\
\hline 3 & $b l a_{\mathrm{CTX}-\mathrm{M}-1}$ & $\operatorname{IncI} 1 \alpha$ & 88 & Removal of lungs, hart, liver, tongue \\
\hline 4 & $b l a_{\mathrm{CTX}-\mathrm{M}-1}$ & $\operatorname{IncI} 1 \alpha$ & 10 & $\begin{array}{l}\text { Dressing (first, second), removal abdominal } \\
\text { fat, diaphragm }\end{array}$ \\
\hline 5 & $b l a_{\mathrm{CTX}-\mathrm{M}-1}$ & IncN & 93 & Removal of head, spinal cord \\
\hline 6 & bla $_{\mathrm{CTX}-\mathrm{M}-1}$ & IncN & 93 & Removal of head, spinal cord \\
\hline 7 & $b l a_{\mathrm{CTX}-\mathrm{M}-1}$ & $\mathrm{IncN}$ & 93 & Organs (tongues, hearts, livers, kidneys) \\
\hline 8 & $b l a_{\mathrm{CTX}-\mathrm{M}-1}$ & IncFIA-FII & 131 & Packaging \\
\hline 9 & $b l a_{\mathrm{CTX}-\mathrm{M}-15}$ & IncK & 156 & Cutting room \\
\hline 10 & bla $_{\mathrm{CTX}-\mathrm{M}-15}$ & incFIB-FII & 410 & Deboning area \\
\hline 11 & $b l a_{\mathrm{CTX}-\mathrm{M}-15}$ & IncFIA-FII & 131 & Dehairing and hanging part \\
\hline 12 & $b l a_{\mathrm{CTX}-\mathrm{M}-24}$ & $-*$ & 354 & Packaging \\
\hline 13 & $b l a_{\mathrm{CTX}-\mathrm{M}-27}$ & IncFIA-FIB-FII & 131 & Other (e.g. technical services) \\
\hline 14 & bla $a_{\mathrm{CTX}-\mathrm{M}-27}$ & IncFIB-FII & 131 & Cutting room \\
\hline 15 & $b l a_{\mathrm{CTX}-\mathrm{M}-55}$ & $-*$ & 95 & Removal of lungs, hart, liver, tongue \\
\hline 16 & $b l a_{\mathrm{SHV}-12}$ & IncFIB-FIC-FII & 665 & Removal of lungs, hart, liver, tongue \\
\hline 17 & $b l a_{\mathrm{CMY}-2}$ & $\operatorname{IncI} 1 \alpha$ & 752 & Cutting room \\
\hline 18 & $b l a_{\mathrm{CMY}-2}$ & $\operatorname{IncI} 1 \alpha$ & 752 & Cutting room \\
\hline 19 & $b l a_{\mathrm{DHA}-1}$ & IncFIA-FII & 38 & Stabbing and bleeding part \\
\hline
\end{tabular}

* No successful transformation or conjugation.

(OR 0·31, CI 0.09-1·12) as well as travelling (OR 0·36, CI $0 \cdot 13-1 \cdot 04)$. None of the other potential risk factors (nationality, consumption of raw meat, hospitalization, use of antimicrobials, living on a farm) or confounders (age, gender) were significantly associated with ESBL carriage. In multivariate analysis, the effects of smoking and travelling appeared independent of job exposure (only a slight change in OR) and did not remain in the final model. Therefore the final model only contained job exposure as a risk factor for ESBL carriage.

When looking at ESBL carriage by nationality, Romanian workers had a higher prevalence (five out of $41(12 \cdot 2 \%)$ ) compared with the other three well-represented nationalities: Hungarian (one out of $46(2 \cdot 2 \%)$ ), Dutch (three out of $60(5 \cdot 0 \%))$ and Polish (five out of $119(4 \cdot 2 \%))$. However, 23 out of $41(56 \cdot 1 \%)$ of the Romanians worked in the higher exposure' group, which is a considerably higher percentage than within Hungarian, Dutch and Polish slaughterhouse workers (seven out of $46(15 \cdot 2 \%)$, nine out of $60(15.0 \%)$ and 30 out of $119(25 \cdot 2 \%)$ respectively). When in the final model the effect of job exposure was adjusted for Romanian nationality, the association between ESBL carriage and job exposure hardly changed (OR 4.85, CI 1.54-15.24). No significant interaction between Romanian nationality and job exposure was observed for ESBL carriage.

Focusing on $b l a_{\mathrm{CTX}-\mathrm{M}-1}$ gene solely, the prevalence was $7 \cdot 4 \%(7 / 95)$ in the 'higher exposure' group and $0.4 \%(1 / 233)$ in the other group. When analysis was restricted for $b l a_{\mathrm{CTX}-\mathrm{M}-1}$ alone, the association between ESBL carriage and exposure group was confirmed (OR 18·46, CI 2·24-152·16).

From the 74 participants who reported to have more than one job title, 11 participants mentioned job titles not within the same exposure group. This misclassification of exposure might have changed the association between exposure and ESBL carriage. When a sensitivity analysis was performed by switching these 11 participants from the 'higher exposure' to the 'lower exposure' group, the observed association between ESBL carriage and occupational exposure did not change significantly and had a similar point estimate (OR 5·36, CI 1·89-15·25).

\section{DISCUSSION}

The study revealed that slaughterhouse workers were more likely to carry ESBL when working in the early slaughtering steps (before chilling of the pig carcasses) than slaughterhouse workers working from 
this slaughter step forward, i.e. working in the cooling, cutting and deboning area. Overall prevalence of ESBL carriage was $4 \cdot 8 \%$, which is more or less comparable to numbers found in two recent Dutch studies in residents of Amsterdam (8.6\%) and residents living in the vicinity of livestock farms $(4 \cdot 5 \%)$ [18, 19]. However, the ESBL prevalence differed between the assumed higher and lower exposed groups (10.5 vs. $2.6 \%$ ) pointing at higher occupational exposures during specific tasks performed by individual slaughterhouse workers.

A previous study in the same slaughterhouse showed a decline in presence and counts of Salmonella on skin surface and the exterior of carcasses from bleeding till chilling [20]. In addition, a decline in presence of $E$. coli during the slaughter process, especially after chilling of the pig carcasses, has been described in literature [14, 15, 21, 22]. It is likely that ESBL-producing $E$. coli shows the same decline as $E$. coli in general, although we can only assume since exposure to ESBL was not measured in this study. This could explain the higher carriage of ESBL among slaughterhouse workers when involved in the slaughter steps before chilling. For some slaughter steps only low numbers of participants could be included. As a consequence, it was not possible to estimate differences in ESBL carriage in more detail. However, when focusing on the descriptive figures, ESBL carriage is considerably higher when working in the slaughter steps 'removal of lungs, heart, liver, tongue' and 'removal of head and spinal cord'. Exposure to ESBL might be higher for workers in these slaughter steps, because both steps involve handling of the throat area, including the pharyngeal tonsils which are colonized with high counts of several bacteria (potentially including ESBL-producing E. coli) $[23,24]$.

In this study, $b a_{\text {CTX-M-1 }}$ was the most predominantly detected ESBL gene in pig slaughterhouse workers. Out of the ESBL-positive slaughterhouse workers, eight were carrying $b l a_{\text {СTX-M-1 }}(50 \%)$, which is significantly higher than the proportions of $b l a_{\mathrm{CTX}-\mathrm{M}-1}$ reported in two Dutch studies. In ESBL-positive residents of Amsterdam and ESBL-positive residents living in the vicinity of livestock farms 26 out of 145 $(18 \%)$ and 13 out of $99(13 \%)$ carried a bla $a_{\text {CTX-M-1 }}$ gene, respectively $[18,19]$. In addition, bla $a_{\mathrm{CTX}-\mathrm{M}-1}$ is also the most frequently found ESBL gene in slaughter pigs in the Netherlands [25]. Moreover, pig farmers were found to carry the same ESBL gene type as exclusively or predominantly detected in their pigs, of which $b l a_{\text {CTX-M-1 }}$ was most frequently found in both of them [3]. In contrast, bla $a_{\mathrm{CTX}-\mathrm{M}-15}$ has been found mostly in humans in a clinical setting and in the Dutch human population, but not that often in livestock [2, 18, 26]. A great diversity was seen in STs; therefore clonal transmission between slaughterhouse workers is probably not the dominant route of transmission. Besides, half of the STs (ST10, ST38, ST88, ST93, ST354) have been previously associated with $E$. coli from pig origin [8, 27, 28]. In addition, IncN and IncI1 plasmids are known to play a role in the dissemination of $b l a_{\mathrm{CTX}-\mathrm{M}-1}$ in $E$. coli in livestock, including pigs [29-31]. Although no samples from carcasses or slaughter products were obtained, these results regarding ESBL gene types, plasmids and STs, suggesting transmission from animals to humans.

Besides occupational exposure, none of the analysed determinants (nationality, consumption of raw meat, hospitalization, use of antimicrobials, living on a farm, travelling, age, gender and smoking) were found to be risk factors for ESBL carriage in slaughterhouse workers. ESBL carriage was higher in slaughterhouse workers with a Romanian nationality compared with other nationalities, although the association between ESBL carriage and occupational exposure remained when adjusting for Romanian nationality. Besides that, the effect of being in the 'higher exposure' group is similar for Romanian slaughterhouse workers as for the other nationalities, considering the non-significant interaction. Also, in three out of five Romanian ESBL carriers the ESBL gene type detected was $b l a_{\text {CTX-M-1. }}$. Smoking and travelling were protective factors for ESBL carriage univariately, although they did not retain in the final model. From the 173 non-Dutch slaughterhouse workers who reported their travelling destiny, $88 \%$ travelled to their country of origin. Although travelling frequencies were not assessed, travelling might be interpreted as long distance commuting. To our knowledge, there is no explanation described in literature for any effect of smoking on ESBL carriage.

Although ESBL carriage was detected in slaughterhouse workers, the risk of acquiring ESBL-producing $E$. coli when handling meat intensively seems to be limited. When this is extrapolated to consumers, exposure to ESBL in pork through handling might not be of a high public health concern. In combination with environmental exposure data, this information can be used in formal risk assessments. Although not addressed in this study design, duration and persistence of ESBL carriage can vary greatly [32, 33]. 
Duration of ESBL carriage is not only important for assessing the risk of infection, but for the risk of transmission of ESBLs from slaughterhouse workers into the general population as well.

The results suggest that the overall carriage in slaughterhouse workers is comparable with the Dutch population, but the proportion of the $b l a_{\text {СТХ-M-1 }}$ gene (commonly found in livestock) is higher. Differences exist between slaughterhouse workers depending on their job tasks. A higher prevalence of ESBL carriage was found in slaughterhouse workers working before the chilling process of the carcasses compared to workers in the cooling area, cutting and deboning departments.

\section{ACKNOWLEDGEMENTS}

The authors would like to thank all participated slaughterhouse workers and other involved employees from Vion in Boxtel for participation and all field workers and laboratory workers for assistance. The authors would also like to thank Alejandro Dorado-Garcia for assistance on data analysis. This work was supported by the 1Health4Food (1H4F) project under the ESBLAT consortium (TKI-AF-12067); and by the European Commission, 7th Framework Programme for Research, technological Development and Demonstration (FP7/2007-2013-613754).

Preliminary results from this study were presented in an oral presentation at the 26th Conference on Epidemiology in Occupational Health in Barcelona, Spain, 2016 (abstract 121).

\section{DECLARATION OF INTEREST}

None.

\section{REFERENCES}

1. Pitout JD, Laupland KB. Extended-spectrum beta-lactamase-producing Enterobacteriaceae: an emerging public-health concern. Lancet Infectious Diseases 2008; 8: 159-166.

2. Ewers C, et al. Extended-spectrum $\beta$-lactamase-producing and AmpC-producing Escherichia coli from livestock and companion animals, and their putative impact on public health: a global perspective. Clinical Microbiology and Infection 2012; 18: 646-655.

3. Dohmen W, et al. Carriage of extended-spectrum beta-lactamases in pig farmers is associated with occurrence in pigs. Clinical Microbiology and Infection: the Official Publication of the European Society of Clinical Microbiology and Infectious Diseases 2015; 21: 917-923.
4. Kola A, et al. High prevalence of extended-spectrumbeta-lactamase-producing Enterobacteriaceae in organic and conventional retail chicken meat, Germany. Journal of Antimicrobial Chemotherapy 2012; 67: 2631-2634.

5. Dierikx C, et al. Extended-spectrum- $\beta$-lactamase- and AmpC- $\beta$-lactamase-producing Escherichia coli in Dutch broilers and broiler farmers. Journal of Antimicrobial Chemotherapy 2013; 68: 60-67.

6. Hammerum AM, et al. Characterization of extendedspectrum beta-lactamase (ESBL)-producing Escherichia coli obtained from Danish pigs, pig farmers and their families from farms with high or no consumption of third- or fourth-generation cephalosporins. Journal of Antimicrobial Chemotherapy 2014; 69: 2650-2657.

7. Geser $\mathbf{N}$, et al. Fecal carriage of extended-spectrum beta-lactamase-producing Enterobacteriaceae in swine and cattle at slaughter in Switzerland. Journal of Food Protection 2011; 74: 446-449.

8. Ramos S, et al. Clonal diversity of ESBL-producing Escherichia coli in pigs at slaughter level in Portugal. Foodborne Pathogens and Disease 2013; 10: 74-79.

9. Randall LP, et al. Prevalence of extended-spectrumbeta-lactamase-producing Escherichia coli from pigs at slaughter in the UK in 2013. Journal of Antimicrobial Chemotherapy 2014; 69: 2947-2950.

10. Bardon J, et al. Prevalence and characteristics of Escherichia coli strains producing extended-spectrum beta-lactamases in slaughtered animals in the Czech Republic. Journal of Food Protection 2013; 76: 1773-1777.

11. Nijsten R, et al. Resistance in faecal Escherichia coli isolated from pigfarmers and abattoir workers. Epidemiology and Infection 1994; 113: 45-52.

12. Thorsteinsdottir TR, et al. Prevalence and genetic relatedness of antimicrobial-resistant Escherichia coli isolated from animals, foods and humans in Iceland. Zoonoses and Public Health 2010; 57: 189-196.

13. Alali WQ, et al. Longitudinal study of antimicrobial resistance among Escherichia coli isolates from integrated multisite cohorts of humans and swine. Applied and Environmental Microbiology 2008; 74: 3672-3681.

14. Wu S, et al. Prevalence of tetracycline resistance and genotypic analysis of populations of Escherichia coli from animals, carcasses and cuts processed at a pig slaughterhouse. International Journal of Food Microbiology 2009; 135: 254-259.

15. Bouvet $\mathbf{J}$, et al. Effects of slaughter processes on pig carcass contamination by verotoxin-producing Escherichia coli and E. coli O157:H7. International Journal of Food Microbiology 2002; 77: 99-108.

16. Dierikx CM, et al. Occurrence and characteristics of extended-spectrum- $\beta$-lactamase- and AmpC-producing clinical isolates derived from companion animals and horses. Journal of Antimicrobial Chemotherapy 2012; 67: 1368-1374.

17. Liakopoulos A, et al. Extended-spectrum Cephalosporinresistant Salmonella enterica serovar Heidelberg Strains, the Netherlands(1). Emerging Infectious Diseases 2016; 22: 1257-1261.

18. Reuland EA, et al. Prevalence and risk factors for carriage of ESBL-producing Enterobacteriaceae in Amsterdam. 
The Journal of Antimicrobial Chemotherapy 2016; 71: 1076-1082.

19. Wielders CC, et al. Extended-spectrum beta-lactamaseand pAmpC-producing Enterobacteriaceae among the general population in a livestock-dense area. Clinical Microbiology and Infection: the Official Publication of the European Society of Clinical Microbiology and Infectious Diseases 2016.

20. van Hoek AH, et al. A quantitative approach towards a better understanding of the dynamics of Salmonella spp. in a pork slaughter-line. International Journal of Food Microbiology 2012; 153: 45-52.

21. Lenahan M, et al. The potential use of chilling to control the growth of Enterobacteriaceae on porcine carcasses and the incidence of $E$. coli $\mathrm{O} 157: \mathrm{H} 7$ in pigs. Journal of Applied Microbiology 2009; 106: 1512-1520.

22. Tamplin ML, et al. Salmonella spp. and Escherichia coli biotype I on swine carcasses processed under the hazard analysis and critical control point-based inspection models project. Journal of Food Protection 2001; 64: 1305-1308.

23. Lăpuşan A, et al. The importance of pig tonsils removal for the final assessment of the carcasses' hygiene quality. Scientific Works - University of Agronomical Sciences and Veterinary Medicine, Bucharest Series C, Veterinary Medicine 2012; 58: 347-352.

24. Lowe BA, et al. Microbial communities in the tonsils of healthy pigs. Veterinary Microbiology 2011; 147: 346357.

25. Central Veterinary institute of Wageningen University. Dutch Food and Consumer Product Safety Authority (NVWA). Monitoring of antimicrobial resistance and antibiotic usage in animals in the Netherlands (MARAN) 2015 [cited 7 September 2015]. (https:// www.wageningenur.nl/upload_mm/6/b/0/ba75d7f7-e1274da0-bdb6-8b506aedf250_NethmapMaran2015.pdf)
26. Voets GM, et al. Population distribution of betalactamase conferring resistance to third-generation cephalosporins in human clinical Enterobacteriaceae in the Netherlands. PLoS ONE 2012; 7: e52102.

27. Garcia-Cobos S, et al. Molecular typing of Enterobacteriaceae from pig holdings in North-Western Germany reveals extended-spectrum and $\mathrm{AmpC}$ beta-lactamases producing but no Carbapenem resistant ones. PLoS ONE 2015; 10: e0134533.

28. Herrero-Fresno A, Larsen I, Olsen JE. Genetic relatedness of commensal Escherichia coli from nursery pigs in intensive pig production in Denmark and molecular characterization of genetically different strains. Journal of Applied Microbiology 2015; 119: 342-353.

29. Dolejska M, et al. Characterization of IncN plasmids carrying bla CTX-M-1 and qnr genes in Escherichia coli and Salmonella from animals, the environment and humans. Journal of Antimicrobial Chemotherapy 2013; 68: 333-339.

30. Rodrigues C, et al. IncI1/ST3 and IncN/ST1 plasmids drive the spread of blaTEM-52 and blaCTX-M-1/-32 in diverse Escherichia coli clones from different piggeries. Journal of Antimicrobial Chemotherapy 2013; 68: 2245-2248.

31. Zurfluh K, et al. Replicon typing of plasmids carrying bla CTX-M-1 in Enterobacteriaceae of animal, environmental and human origin. Frontiers in Microbiology 2014; 5: 555.

32. Tham J, et al. Duration of colonization with extendedspectrum beta-lactamase-producing Escherichia coli in patients with travellers' diarrhoea. Scandinavian Journal of Infectious Diseases 2012; 44: 573-577.

33. Birgand G, et al. Duration of colonization by extendedspectrum beta-lactamase-producing Enterobacteriaceae after hospital discharge. American Journal of Infection Control 2013; 41: 443-447. 